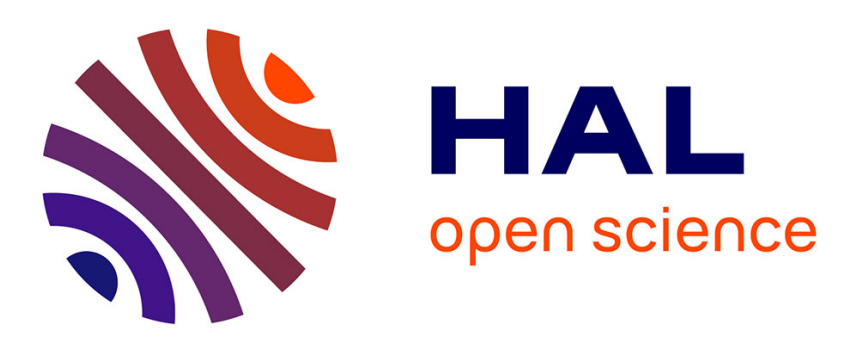

\title{
Impact of hemp shiv extractives on hydration of portland cement
}

Guillaume Delannoy, Sandrine Marceau, Philippe Gle, Etienne Gourlay, Marielle Gueguen Minerbe, Dinarzed Diafi, Sofiane Amziane, Fabienne Farcas

\section{- To cite this version:}

Guillaume Delannoy, Sandrine Marceau, Philippe Gle, Etienne Gourlay, Marielle Gueguen Minerbe, et al.. Impact of hemp shiv extractives on hydration of portland cement. Construction and Building Materials, 2020, 244, 36 p. 10.1016/j.conbuildmat.2020.118300 . hal-02472950

\section{HAL Id: hal-02472950 https://hal.science/hal-02472950}

Submitted on 10 Feb 2020

HAL is a multi-disciplinary open access archive for the deposit and dissemination of scientific research documents, whether they are published or not. The documents may come from teaching and research institutions in France or abroad, or from public or private research centers.
L'archive ouverte pluridisciplinaire HAL, est destinée au dépôt et à la diffusion de documents scientifiques de niveau recherche, publiés ou non, émanant des établissements d'enseignement et de recherche français ou étrangers, des laboratoires publics ou privés. 


\title{
IMPACT OF HEMP SHIV EXTRACTIVES ON HYDRATION OF PORTLAND CEMENT
}

\author{
Guillaume Delannoy ${ }^{\mathrm{a}}$, Sandrine Marceau ${ }^{\mathrm{a}}$, Philippe Glé ${ }^{\mathrm{bc}}$, Etienne Gourlay ${ }^{\mathrm{b}}$, Marielle Guéguen-Minerbe ${ }^{\mathrm{a}}$, \\ Dinarzed Diafia, Sofiane Amziane ${ }^{d}$, Fabienne Farcas ${ }^{a}$ \\ ${ }^{a}$ MAST-CPDM, Univ Gustave Eiffel, IFSTTAR, F-77454 Marne-la-Vallée, France; \\ quillaume.delannoy@ifsttar.fr; sandrine.marceau@ifsttar.fr; marielle.gueguen@ifsttar.fr; \\ dinarzed.diafi@ifsttar.fr; fabienne.farcas@ifsttar.fr
}

b CEREMA, Laboratory of Strasbourg, 11 rue Jean Mentelin, BP 9, 67035 Strasbourg Cedex 2, France; philippe.gle@cerema.fr; etienne.gourlay@cerema.fr

c CEREMA, IFSTTAR, UMRAE, 11 rue Jean Mentelin, BP 9, 67035 Strasbourg Cedex 2, France; d University of Clermont Auvergne, Institut Pascal, UMR 6602, 63174 Aubière Cedex, France. sofiane.amziane@uca.fr

Corresponding author: sandrine.marceau@ifsttar.fr

\begin{abstract}
When formulating materials containing an hydraulic binder and plant particles, the setting of the binder may be slowed or prevented by the compounds extracted from the plant. In this article, a methodology is fixed to analyse three types of hemp shiv and to study the variability of the composition of extractives and their influence on the hydration of cement. Isothermal calorimetric measurements have shown that one type of shiv caused a greater delay in the setting of the cement. Analysis of free compounds extracted from the plant has shown that this shiv has a higher content of extractives, and in particular, of sugar. By using the same quantities of standard sugars, it was found that the measured sugar content could not, in and of itself, account for the delay in hydration measured in the presence of shiv. Other extracted molecules, such as phenolic compounds, also play a part in the hydration of the cement.
\end{abstract}


Keywords: calorimetry; retardation; Portland cement; vegetal; extractives; hemp, hydration

\section{INTRODUCTION}

With a view to reducing the environmental impact of buildings, bio-based materials are being used increasingly in building projects. In particular, this is the case with bio-based insulators, known as vegetal concrete, formulated mainly using vegetal aggregates such as shiv, made from hemp. The mechanical resistance of the material comes from the addition of a mineral binder which covers the particles. In a study on the durability of hemp concrete (hempcrete), samples corresponding to a wall formulation were made up using binders and shiv compliant with the building codes imposed by the French organisation of hemp construction [1]. With these materials, compressive strengths lower than those expected were measured and attributed to a lack of hydration of the binders due to the incompatibility of the binder-vegetal aggregate couple [2]. Similar results have been found in other works [3,4] and have been explained by the perturbation of hydration reactions of cement in the presence of molecules from the shiv. Shiv is a ligno-cellulosic material, obtained from the shredded stem of the hemp plant, and made of a mixture of cell walls and free compounds that can easily be extracted with water or organic solvents.

The plant cell walls are composed of a matrix of amorphous polymers (hemicelluloses, lignins and pectins), reinforced with crystalline cellulose microfibers [5]. Cellulose and hemicelluloses are saccharides, commonly known as sugars. The simplest saccharide units are monosaccharides, such as glucose or fructose. Cellulose, which is the majority compound in shiv, is a polysaccharide composed solely of glucose. Hemicelluloses are polysaccharides composed of various types of monosaccharides such as fructose, xylose or mannose, but also uronic acids, which are oxidised forms of saccharides. While monosaccharides

or oligosaccharides are highly soluble in water at a neutral $\mathrm{pH}\left(4.2 \mathrm{~kg} \cdot \mathrm{L}^{-1}\right.$ at $20^{\circ} \mathrm{C}$ for sucrose [6]), hemicelluloses and cellulose are insoluble. Nonetheless, hemicelluloses can be dissolved in basic solutions [7]. Lignins, which are hydrophobic compounds formed by the polymerisation of phenolic alcohols, are not soluble in water. Finally, pectins are linear polysaccharides with varying degrees of branching, made of a linear chain of galacturonic acids. During the process of transformation of the hemp stems, during retting, the degradation of pectin under the influence of enzymes synthesised by micro-organisms allows the fibres 
to be separated from the shiv. Unlike the other compounds in the cell walls, certain pectins can be extracted using water.

Numerous other molecules not found in the walls, such as polyphenols, oligosaccharides, fatty acids and terpenes, are also present in small proportions in shiv. These molecules are soluble in different solvents and are therefore extractible in the same way as pectin. Among the molecules extractible from shiv are also oligomers of hemicelluloses and lignin, along with proteins, lipids, waxes and ash [5]. These compounds are present in different proportions as a function not only of the nature of the plant matter but also of the way in which the plant was grown, any processes that it has undergone, the way in which it has been stored, etc. $[3,8]$.

When mixing and implementing hempcrete, the extractive molecules diffuse in the mixing water and slow down the kinetics of binder hydration [9-11]. This may alter the properties of the materials - in particular, decreasing their mechanical strength $[2,5,12]$. Certain mechanisms of interaction between the plant molecules and the mineral phases have been identified to explain this result. They involve different types of molecules extracted from the aggregates:

- The adsorption of monosaccharides to anhydrous cement grains delays the setting by reversible physisorption $[8,9,13]$. For this to happen, the molecules must be charged, which is the case with monosaccharides, known as reducing sugars [14]. In a basic environment, enolate ions, negatively charged and relatively stable, are formed and can adsorb by electrostatic links to the surface of the cement grains (for the most part, positively charged), limiting access to water for non-hydrated grains.

- the capture of calcium ions [13,15-17] by uronic acids, phenolic compounds, certain polysaccharides such as pectin $[7,18]$ or acids stemming from alkaline degradation of the saccharides $[19,20]$ also contributes. The captured calcium ions are then no longer available to take part in hydration reactions.

- nucleation sites may be blocked by non-reducing sugars, such as sucrose or stachyose, which can form complexes in the presence of calcium ions, and affix to the hydrates [10,21]. These molecules irreversibly prevent the growth of hydrates; CSH can no longer precipitate at that site. We then speak of the poisoning of the nucleation sites $[9,22,23]$. 
- the formation of a water-impermeable hydrate barrier can be linked to the very rapid hydration of aluminates $\mathrm{C}_{4} \mathrm{AF}$ in the presence of sugars $[13,17]$.

These mechanisms depend on the nature and quantity of the plant molecules extracted when the vegetal concretes are being formulated. To limit the effects of the vegetal matter on binder hydration, certain studies have proposed subjecting the fibres or aggregates to a range of treatments, which may be costly [3,24-27], or adapting the formulation of the binders and their additives [28-32]. There is also a third feasible solution: to select plant materials that are compatible with the mineral binders, based on their levels of extractives. A batch of aggregates which has too high a content of extractives poses a real danger of delaying the setting of the binder, and thus altering the properties of the hardened material, and its durability.

Despite the knowledge of these interactions between plants and mineral binders and the existence of building regulations, problems of pulverization at the core of the materials are regularly reported after their implementation in buildings [33]. In order to develop the use of vegetal concretes for building insulation, it is therefore necessary to characterize the compatibility between a mineral binder and vegetal aggregates by analyzing the extractible compounds of plants. A range of extraction protocols have been used previously to study the influence of vegetal extractives on the hydration of mineral binders. The parameters used are listed Table $1[3,4,7,11,19,23,24,34]$. The immersion time, temperature, type of extraction solution and the water/vegetal ratio are parameters which vary from one study to the next, and which have a significant influence on the type and quantity of extractives measured. This variability of the extraction conditions makes it difficult to compare the results of those studies, and there is no universally accepted protocol. 
Table 1. Synthesis of extraction protocols of vegetal fibres or aggregates depending on the solution, heating of the solution, the time of extraction, the liquid to vegetal mass ratio $(L / N)$, and the quantification of total amount of extractives, of sugars and acids

\begin{tabular}{|c|c|c|c|c|c|c|c|c|c|c|c|}
\hline \multirow{2}{*}{ Vegetal } & \multicolumn{5}{|c|}{ Solution } & \multirow[t]{2}{*}{$\mathrm{T}^{\circ} \mathrm{C}$} & \multirow[t]{2}{*}{ Time } & \multirow[t]{2}{*}{ L/V } & \multicolumn{3}{|c|}{ Quantification } \\
\hline & $\begin{array}{l}\frac{d}{ \pm} \\
\frac{\pi}{3}\end{array}$ & $\frac{\mathfrak{N}}{\stackrel{\widetilde{0}}{\tilde{J}}}$ & $\begin{array}{l}\text { I } \\
\text { O } \\
\text { z }\end{array}$ & 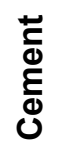 & $\begin{array}{l}\bar{N} \\
\bar{U}\end{array}$ & & & & $\begin{array}{l}\bar{\pi} \\
\stackrel{0}{0} \\
\qquad\end{array}$ & $\begin{array}{l}\stackrel{\infty}{\pi} \\
\stackrel{0}{D} \\
\stackrel{D}{D}\end{array}$ & $\frac{n}{\frac{0}{0}}$ \\
\hline Hemp fibre [7] & $\star$ & $\star$ & $\star$ & & $\star$ & & $1 \mathrm{~h}$ & 10 & & $\star$ & $\star$ \\
\hline Sun flower, lavender [4] & $\star$ & & & & & 100 & $1 \mathrm{~h}$ & & $\star$ & & \\
\hline Miscanthus [34] & $\star$ & & & & & 100 & $2 \mathrm{~h}$ & 5 & & & \\
\hline $\begin{array}{l}\text { Bagasse fibre, Coconut } \\
\text { fibre, Hemp fibre, Oil palm } \\
\text { fibre, Spruce wood, Water } \\
\text { hyacinth [23] }\end{array}$ & $\star$ & & & & & 80 & $2 \mathrm{~h}$ & 5 & $\star$ & $\star$ & $\star$ \\
\hline Hemp shiv [3] & $\star$ & & & & & & $24 \mathrm{~h}$ & 10 & $\star$ & $\star$ & \\
\hline Wood powder [11] & $\star$ & & & $\star$ & & 80 & $24 \mathrm{~h}$ & 1 & $\star$ & & \\
\hline Wood [19] & $\star$ & $\star$ & & $\star$ & & & $24 \mathrm{~h}$ & 50 & $\star$ & & \\
\hline Lavender [24] & $\star$ & & & & & & $72 \mathrm{~h}$ & 14 & & & \\
\hline
\end{tabular}

The final objective will be to set criteria for the selection of plant particles. to avoid this type of pathology. It is for this purpose that, in this study, we seek a simple method which would allow us to distinguish between different kinds of shiv on the basis of their content of extractives, and select those which have lower levels. With this goal in mind, a Portland cement is used for the study, because its setting mechanisms have already been documented and studied. Three types of shiv are chosen. The first is the shiv which we used previously in the durability study, where a lack of hydration was observed [2]. The other two shives are of different origins, and were used in an earlier study, where no problem was found with the hydration [35].

In this article, the influence of the different shives on the binder hydration time is first studied. Secondly, an extraction method is established, based on the data from previous studies. Next, once the protocol has been established, the amount of extractive molecules in the mixture is quantified. We have focused, in particular, 
on sugar content, because sugars are the molecules which are most often cited as being responsible for delayed setting $[3,8]$. Finally, these results are discussed, and we assess the influence of the content of reducing and non-reducing sugars in comparison to that of other compounds extracted from shives on the setting of the hydraulic binder.

\section{MATERIALS AND METHODS}

\subsection{Materials}

\subsubsection{Types of shiv}

Three types of hemp shiv were selected for this investigation, based on observations made during previous studies [2,35]. They are referred to as HS1, HS2 and HS3 (Figure 1). They come from different French hemp producers and comply with the French hemp shiv label [1]. The chemical composition of these types of shiv, presented in Table 2, was determined using the Van Soest method and French standard NF-18122.

Photographs of the three hemp shives, their granulometry curve and their water absorption curves are shown in Figure 1 and Figure 2. These results are obtained by following the recommendations of Technical Committee 236-BBM at France's RILEM [36].

For certain tests, shives are reduced to powder using a bladed crusher, sieved to a particle size of $500 \mu m$ and then dried for 48 hours at $105^{\circ} \mathrm{C}$. HP1, HP2 and HP3 correspond to the hemp powders obtained from HS1, HS2 and HS3 respectively. 
Table 2. Chemical composition of hemp shives determined by Van Soest method

\begin{tabular}{lccc}
\hline Proportion (\%) & Hemp shiv 1 & Hemp shiv 2 & Hemp shiv 3 \\
\hline Cellulose & $53.0 \pm 0.9$ & $54.7 \pm 0.5$ & $54.9 \pm 0.5$ \\
Hemicellulose & $12.1 \pm 0.9$ & $11.5 \pm 0.6$ & $12.0 \pm 0.4$ \\
Lignin & $15.0 \pm 0.2$ & $16.8 \pm 0.2$ & $15.5 \pm 0.3$ \\
Others & $19.9 \pm 2.0$ & $17.0 \pm 1.3$ & $17.6 \pm 1.2$ \\
\hline
\end{tabular}

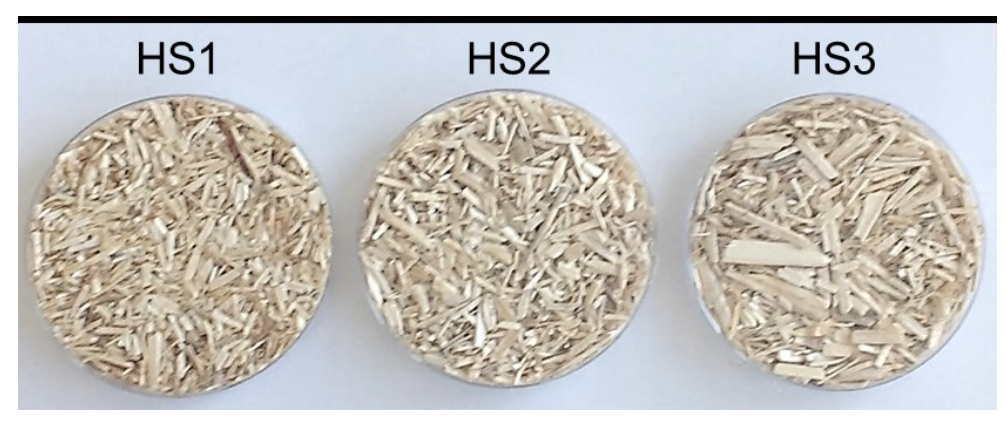

Figure 1. Aggregates of hemp shiv
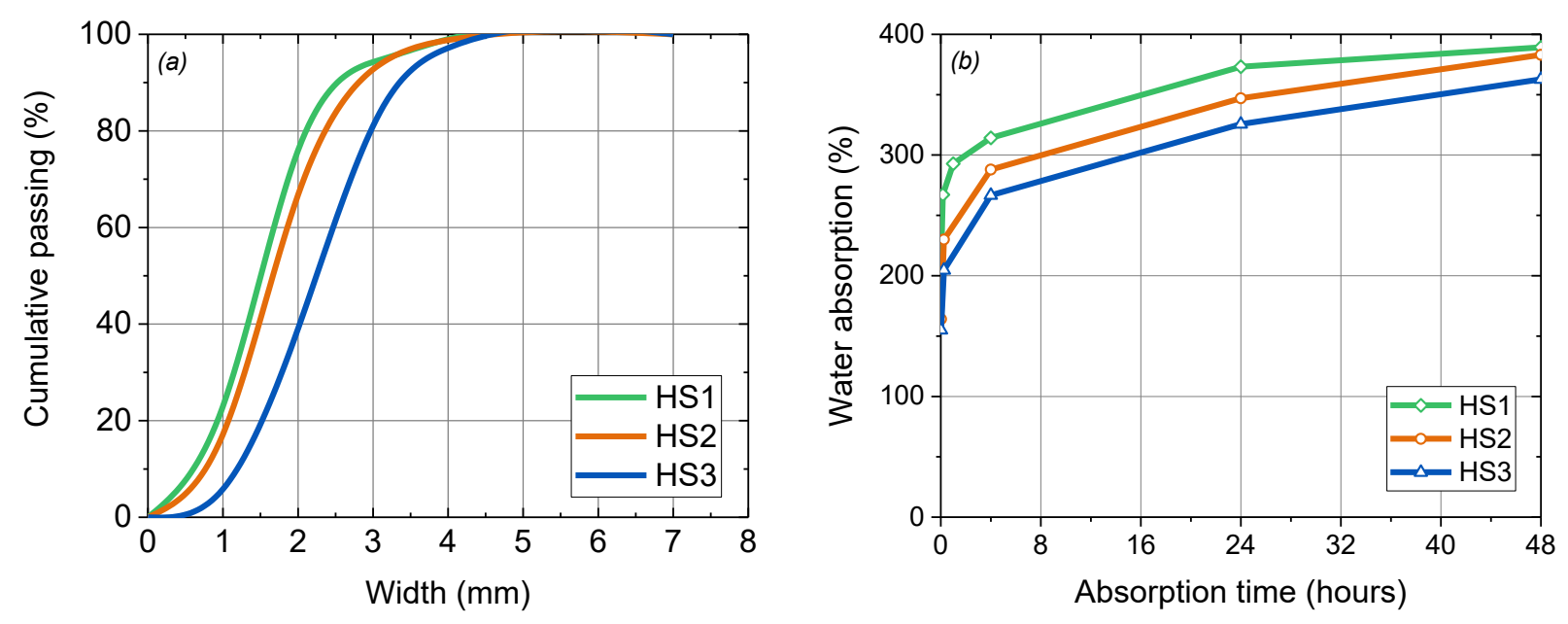

Figure 2. (a) Particle size distribution and (b) water absorption of hemp shives

\subsubsection{Standard sugars}

Standard samples of glucose ( $\mathrm{N}^{\circ}$ CAS 50-99-7), fructose ( $\mathrm{N}^{\circ}$ CAS 57-48-7), sucrose ( $\mathrm{N}^{\circ}$ CAS 57-50-1), xylose ( $\left.\mathrm{N}^{\circ} \mathrm{CAS} 58-86-6\right)$ and mannose ( $\mathrm{N}^{\circ}$ CAS 3458-28-4) for analysis (purity $>99.5 \%$ ) are supplied by Sigma Aldrich. 


\subsubsection{Portland cement}

Depending on the manufacturer's data, the Portland cement CEMI used for this study contains $60 \%$ of $\mathrm{C}_{3} \mathrm{~S}$, $13 \%$ of $\mathrm{C}_{2} \mathrm{~S}, 2 \%$ of $\mathrm{C}_{3} \mathrm{~A}, 13 \%$ of $\mathrm{C}_{4} \mathrm{AF}$ and $4 \%$ of gypsum.

\subsection{Methods}

\subsubsection{Calorimetry}

The binder hydration is measured by isothermal calorimetry at $25^{\circ} \mathrm{C}$ (TA Instruments, TAM AIR 8 , Reference sample of Fontainebleau sand). The heat flux released and the cumulative amount of heat are measured over time in relation to a sample of sand used as a reference. The quantity of sand is adapted to the size of the sample being analysed, so that the specific heat capacities are the same in both test tubes.

The measurements are made on cement paste, cement paste containing shiv powder, hempcrete and cement paste containing standardised sugars. The composition of the different types of samples and the masses analysed are set out in Table 3 . The quantity of shiv present in the samples increases when the binder-to-shiv ratio decreases.

The samples of cement containing shiv powder and the hemp concrete are made up in accordance with the hemp building regulations [1].

Table 3. Formulations of cement pastes and hemp concrete

\begin{tabular}{lcccc}
\hline Sample & $\begin{array}{c}\text { Pure cement } \\
\text { paste }\end{array}$ & $\begin{array}{c}\text { Cement paste + } \\
\text { hemp powder }\end{array}$ & Hemp concrete & $\begin{array}{c}\text { Cement paste + } \\
\text { sugar standards }\end{array}$ \\
\hline $\begin{array}{l}\text { Water to cement } \\
\text { mass ratio }\end{array}$ & 0.5 & 1 & 1 & 0.5 \\
\hline $\begin{array}{l}\text { Vegetal to cement } \\
\text { mass ratio }\end{array}$ & 0 & $0.01,0.02,0.05,0.1$ & 0.5 & 0 \\
\hline $\begin{array}{l}\text { Sample weight in } \\
\text { calorimeter (g) }\end{array}$ & 4 & 4 & 8 & 4 \\
\hline
\end{tabular}




\subsubsection{Dosage of reducing sugars in solution}

The reducing sugars extracted in the solutions are dosed by UV-Visible spectrometry after a redox reaction with dinitrosalicylic acid (DNS). DNS, which is yellow in colour, is reduced by the sugar into aminonitrosalicylic acid (ANS), which is orange-red, absorbing light at a wavelength of 540nm (Figure 3).

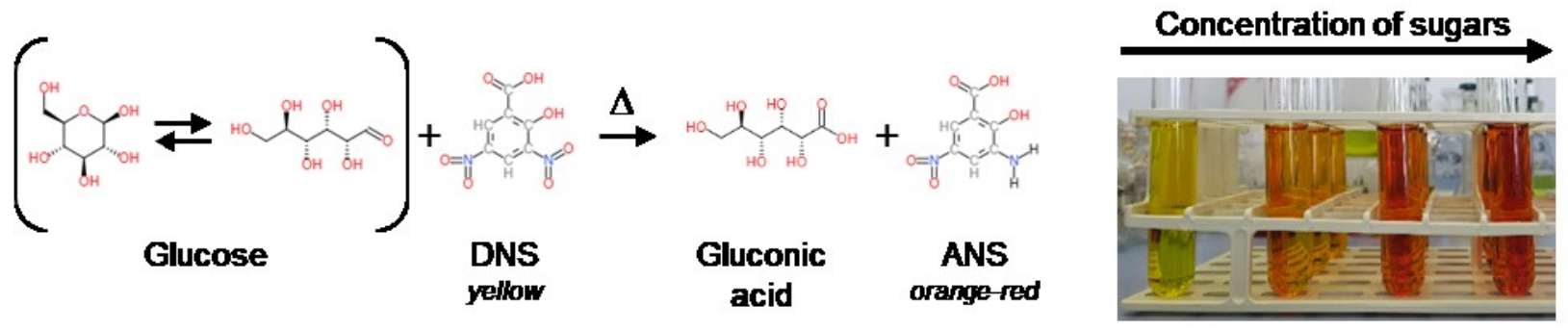

Figure 3. Oxidation-reduction reaction between glucose and DNS and picture of test tubes after reaction without glucose and an increase of sugar concentration

According to the Beer-Lambert law (eq. 1), the absorbance value at $540 \mathrm{~nm}$ corresponds to the concentration of ANS in the solution being analysed, and hence the concentration of reducing sugars present in the initial solution.

$$
\mathrm{A}_{540 \mathrm{~nm}}=\varepsilon 540 \mathrm{~nm} \mathrm{IC}
$$

where:

A540 nm: the absorbance measured at 540nm

E540nm: the molecular absorption coefficient of ANS at 540nm

l: the optical trajectory of the light beam

C: the concentration of ANS

The mass of reducing sugars in solution is then determined in reference to a calibration curve (Figure 4), plotted with solutions of standard sugars (glucose, fructose, xylose and mannose). 


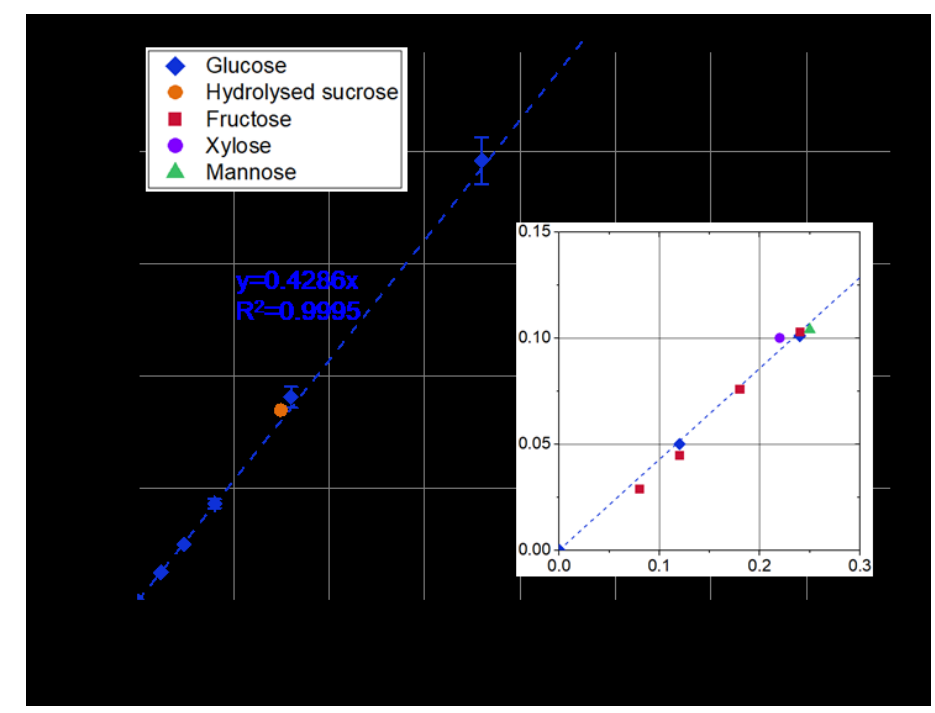

Figure 4. Calibration curve for determination of reducing sugar content by DNS

Equation 2 can be used to calculate the mass of reducing sugars extracted per gram of shiv:

$$
m_{\text {red.sugar } / g}=\frac{A_{540 \mathrm{~nm}} \times V_{\text {extraction }}}{S_{\text {calib }} \times V_{\text {dosage }} \times m_{\text {hemp }}}
$$

where:

$$
\begin{aligned}
& m_{\text {red.sugarlg: }} \text { mass of reducing sugars in } \mathrm{mg} \text { per gram of hemp } \\
& A_{540} \text { : intensity of the absorbance at } 540 \mathrm{~nm} \\
& V_{\text {extraction: volume of water, in } \mathrm{mL} \text {, added for extraction }} \\
& \mathrm{S}_{\text {calib: }} \text { slope of the calibration curve }\left(0.4286 \mathrm{mg}^{-1}-\text { Figure } 4\right) \\
& V_{\text {dosage: }} \text { volume, in } \mathrm{mL} \text {, of extraction solution taken for dosage } \\
& \mathrm{m}_{\text {hemp }} \text { : mass, in grams, of hemp added for extraction }
\end{aligned}
$$

Dosing is carried out on a volume of $1.5 \mathrm{~mL}$ of extraction solution, to which $1 \mathrm{~mL}$ of basic solution of DNS (10g. $\mathrm{L}^{-1}$ of DNS and $16 \mathrm{~g} \cdot \mathrm{L}^{-1}$ of $\mathrm{NaOH}$ ) is added. The resulting solution is heated in a water bath to $100^{\circ} \mathrm{C}$ for 5 minutes. After cooling and dilution by the addition of $7.5 \mathrm{~mL}$ of distilled water, the solution is filtered with a millipore syringe filter, using a cellulose acetate membrane with $0.45 \mu \mathrm{m}$ pore size, before being analysed by UV-visible spectrometry at $540 \mathrm{~nm}$ in a quartz cuvette with a light path of $10 \mathrm{~mm}$. 


\subsubsection{Dosage of total extracted saccharides}

Certain oligosaccharides such as sucrose are not reducing, and cannot be dosed with the procedure described above. To find out the total quantity of sugar extracts, we conduct acid hydrolysis to break all polysaccharides down into monosaccharides, which can then be dosed after reacting with DNS. The formula used is then:

$$
m_{\text {red.sugar }}=\frac{A_{540 \mathrm{~nm}} \times V_{\text {extraction }} \times V_{\text {hydrolysed neutral }}}{S_{\text {calib }} \times V_{\text {dosage }} \times V_{\text {hydrolysée prélevée }} \times m_{\text {hemp }}}
$$

where:

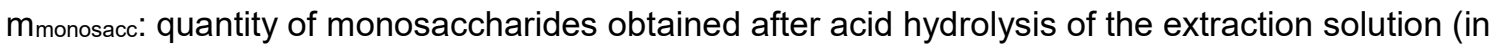
mg) per gram of hemp shiv

A540: intensity of absorbance at 540nm



$V_{\text {hydrolysed neutral: }}$ volume of solution after hydrolysis and $\mathrm{pH}$ buffering $(\mathrm{mL})$

$\mathrm{S}_{\text {calib: }}$ slope of the calibration curve $\left(0.4286 \mathrm{mg}^{-1}\right)$ (Figure 4)

$V_{\text {dosage: }}$ in $\mathrm{mL}$, volume of extraction solution taken for hydrolysis and dosing

Vhydrolysed taken: volume of neutral hydrolysed solution taken for dosing $(\mathrm{mL})$

Mhemp: mass (in g) of hemp added for extraction.

Dosing is conducted on $20 \mathrm{~mL}$ of the extraction solution (Vextraction), which is hydrolysed by the addition of 5 $\mathrm{mL}$ of $2 \mathrm{~mol} . \mathrm{L}^{-1} \mathrm{HCl}$ solution and heated to $100^{\circ} \mathrm{C}$ for 20 minutes. The hydrolysed solution is neutralised by adjusting the $\mathrm{pH}$ to 7 using a $2 \mathrm{~mol} . \mathrm{L}^{-1} \mathrm{NaOH}$ solution, and made up to $50 \mathrm{~mL}$ (Vhydrolysed neutral) with distilled water. We then dose the total sugars with DNS, using the protocol described in section 2.2.2, using $1.5 \mathrm{~mL}$ of that solution ( $V_{\text {hydrolysed taken). }}$

\subsubsection{Statistical analysis of sugar dosage results}

To check whether the differences between the results of dosages of saccharides obtained in different extraction conditions are significant, analysis of variance (ANOVA, Excel - XLToolbox, modified version of Levene's test [37]) is carried out. The ANOVA test used is sufficiently robust so that we do not need to test the normal distribution of the values in a group. It determines a probability "p" that the values in the two 
groups will be statistically identical. The lower the value of $p$, the more significant are the differences measured in series of data. In this article, the results are considered significantly different if the probability $p$ is less than $5 \%(p<0.05)$.

\subsubsection{Colorimetry}

A spectrophotometer (Ci4200, X-Rite) was used to characterise the colour of the solutions of extractives. The analyses were carried out on $10 \mathrm{~mL}$ of solution placed in an optical glass cuvette $31.6 \mathrm{~mm}$ in diameter. The results were pinpointed in the CIELAB colour space by the coordinates $L^{*}$ (luminosity) and the chromaticity coordinates: the $-a^{*} /+a^{*}$ axis from green to red and the $-b^{*} /+b^{*}$ axis from blue to yellow.

\section{RESULTS AND DISCUSSION}

\subsection{Effect of delay on hydration of shiv}

In this part, the effect of shiv on cement hydration is evaluated by isothermal calorimetry measurements. The influence of the content and then of the type of shiv is analysed.

\subsubsection{Effect of shiv content}

The influence of the presence of hemp shiv on the setting of a cement paste is studied by measuring the heat flow released over time from a cement paste, mixtures of cement and powder HP1 and a hemp concrete containing HS1 aggregates. The heat flows over time are presented in Figure 5 for these various mixtures.

Whatever the sample, the addition of the samples into the calorimeter disturbs the equilibrium of the heat flows in the two chambers of the device. An exothermic peak appears which is also visible if the test tubes are empty or contain inert materials. The time taken for the heat flow to stabilise with empty tubes is between 30 minutes and 2 hours. 


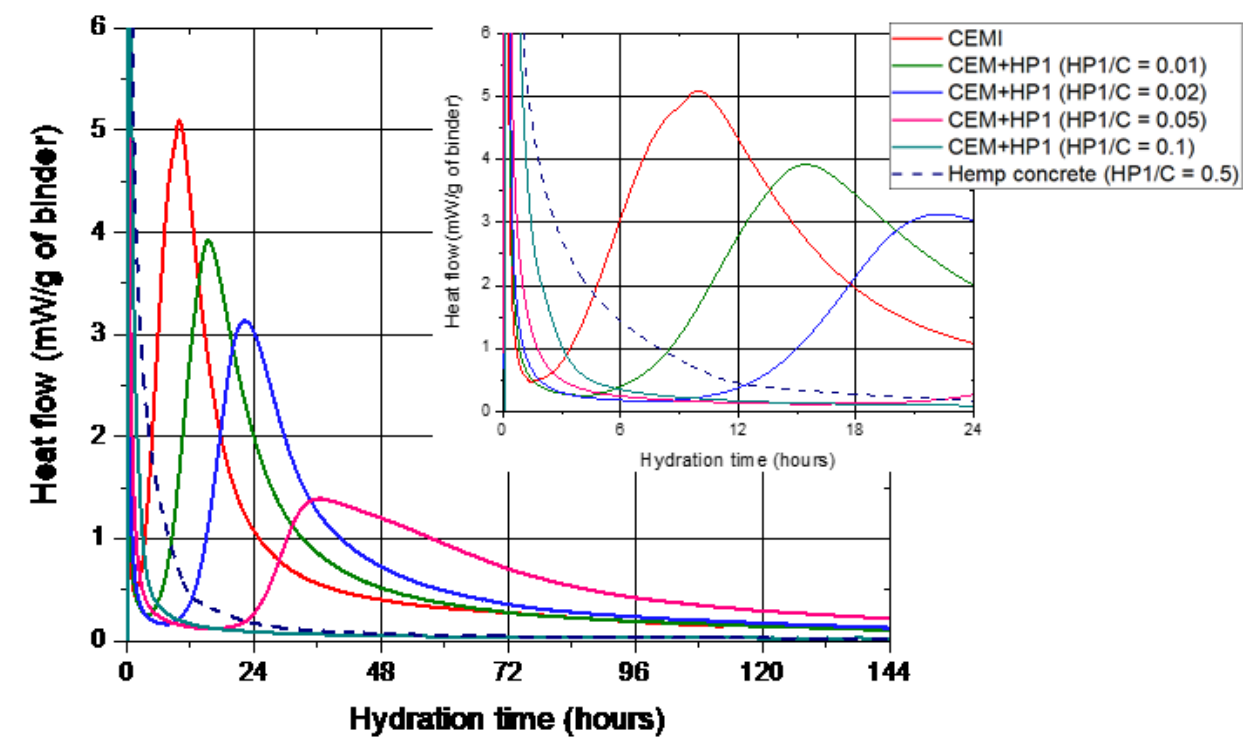

Figure 5. Heat flow for pastes of CEMI, CEMI mixed with hemp shiv powder and hemp concrete

For cement paste, the first reactions occur within the first few minutes of mixing - i.e. before the stabilisation of the heat flow. After 4 hours, the heat flow increases, which is connected to the hydration of the $\mathrm{C}_{3} \mathrm{~S}$ and the precipitation of the portlandite and the $\mathrm{CSH}$ phases:

The maximum of the main hydration peak is reached around 9 hours after mixing of the cement paste. The heat flow then decreases, corresponding to the deceleration of the reactions owing to the layer of hydrates formed on the surface of the anhydrated cement grains, which limits water diffusion. Thus, the hydration is slowed.

By increasing the quantity of shiv from a cement to hemp powder ratio HP/C of 0.01 to a HP/C of 0.05 , the maximum of the main hydration peak shifts towards longer times - respectively 14.5 hours, 22 hours and 35 hours for HP/C ratios of $0.01,0.02$ and 0.05 . The presence of shiv, therefore, causes a delay in the reactions of hydration of the $\mathrm{C}_{3} \mathrm{~S}$ in comparison to $\mathrm{CEMI}$ on its own. When HP/C is equal to 0.1 and for hemp concrete, no peak from the hydration of the $\mathrm{C}_{3} \mathrm{~S}$ can be seen for the first six days. In the case of cement paste containing a HP/C of 0.1 , no signal variation is observed for 21 days. In certain studies where the hydration of the cement in the presence of a powerful delayer such as sucrose is characterised [10], an exothermic peak which corresponds to the hydration of $\mathrm{C}_{3} \mathrm{~S}$ is visible after 90 days monitoring. 
The representation of the cumulated heat over time enables us to more closely observe the phenomena occurring over short spaces of time (Figure 6). For CEMI, the release of heat when the test tube contents are added is around $20 \mathrm{~J} / \mathrm{g}$ of cement. We then see a short period of dormancy, where the cumulated heat is constant. This phase corresponds to the dissolution of the cement grains in the mixing water. When the solution is saturated with ions, the precipitation of the portlandite and $\mathrm{CSH}$, caused by the hydration of the $\mathrm{C}_{3} \mathrm{~S}$, results in an increase of cumulated heat, before the reaction slows down.

Up to a value HP/C of 0.05 , the duration of the dormancy phase increases in line with the quantity of shiv present. The cumulated heats converge on a value of around 350 J/g of cement after 6 days.

The cumulated heats of the paste containing a HP/C of 0.1 and hemp concrete increase rapidly when the test tubes are inserted. This can be explained by the reactions of hydration of the aluminates.

Slowed by the presence of gypsum in the cements themselves, these reactions occur immediately after mixing when sugars are present in the cement paste. Indeed, the sugars catalyse reactions between gypsum and the aluminates $[13,17]$. Then, a dormancy phase can be seen, which lasts for the 21 days of measurement. After 6 days, the cumulated heat is much lower than that measured in cement pastes made with a HP/C varying between 0.01 and 0.05 . From this, we can deduce that the rate of hydration is lower when the quantity of shiv is high. 


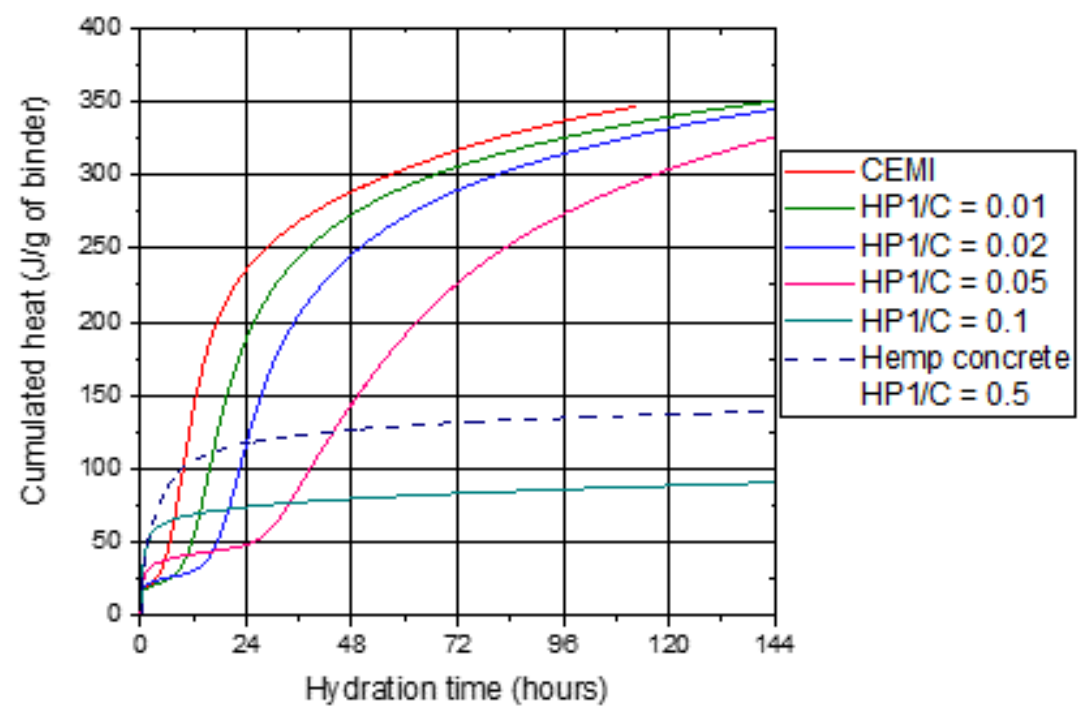

Figure 6. Cumulated heat for pastes of CEMI, CEMI with hemp powder and hemp concrete

In order to assess the compatibility between hemp particles and cement, the equation used by Pasca et al. [38] has been adapted. The CX' factor can be determined using the following equation:

$$
C X^{\prime}=\sqrt[3]{\frac{H R_{\text {max }} * H R_{3.5-96} * t_{\text {max }}^{\prime}}{H R_{\text {max }}^{\prime} * H R_{3.5-96}^{\prime} * t_{\text {max }}} * 100}
$$

Where $\mathrm{HR}_{\max }$ is the maximum heat flow of hemp-cement mixtures, $\mathrm{HR}_{3.5-96}$ is the total heat released between 3.5 and 96 hours, $t_{\max }$ is the time to reach maximum heat flow. $\mathrm{HR}_{\max }{ }^{\prime}, \mathrm{HR}^{\prime}{ }_{3.5-96}$ and $\mathrm{t}_{\max }$ are the values corresponding to the neat cement paste. The values obtained are reported in Table 4.

Table 4. Hemp powder - cement compatibility factor $C X^{\prime}$ for the different mixtures

\begin{tabular}{lccccc}
\hline Sample & $\mathrm{HP} 1 / \mathrm{C}=0.01$ & $\mathrm{HP} 1 / \mathrm{C}=0.02$ & $\mathrm{HP} 1 / \mathrm{C}=0.05$ & $\mathrm{HP} 2 / \mathrm{C}=0.02$ & $\mathrm{HP} 3 / \mathrm{C}=0.02$ \\
\hline $\begin{array}{l}\text { Hemp-cement } \\
\text { compatibility factor } \mathrm{CX}^{\prime}\end{array}$ & 78 & 63 & 38 & 74 & 77 \\
\hline
\end{tabular}

Three groups can be defined to class the hemp-cement compatibility: incompatibility if $C X^{\prime}<40$, moderate compatibility for CX' between 40 and 80 and compatibility for CX' values higher than 80 [38]. In the case of HP1 powder, the components are fairly compatible for HP/C ratio lower than $2 \%$. For higher HP/C values, they are incompatible. 


\subsubsection{Effect of type of shiv}

To study the influence of the nature of the shiv used on the hydration of CEMI cement, isothermal calorimetry measurements were taken on cement pastes with a HP/C value of 0.02 with the three types of shiv. This quantity of hemp powder does not correspond to that of hemp concretes and the particle size is smaller, but these conditions facilitate the homogenisation of the cement pastes necessary for calorimetry measurements and the comparison of the different types of shiv.

The results obtained are presented in Figure 7. The curves illustrating the heat flow over time recorded, for all samples, show the peak corresponding to the hydration of $\mathrm{C}_{3} \mathrm{~S}$, where the maximum is situated at 22 hours, 15 hours and 16.5 hours, for cement pastes containing HP1, HP2 and HP3 respectively, whereas it is at 9 hours for cement on its own.

Isothermal calorimetry confirms that HS1 causes a greater modification in the binder hydration than do HS2 and HS3. This accords with the previous studies conducted with the three types of shiv [2,35], in which the mechanicals strengths of the hemp concretes were found to be very different depending on the type of shiv used. 

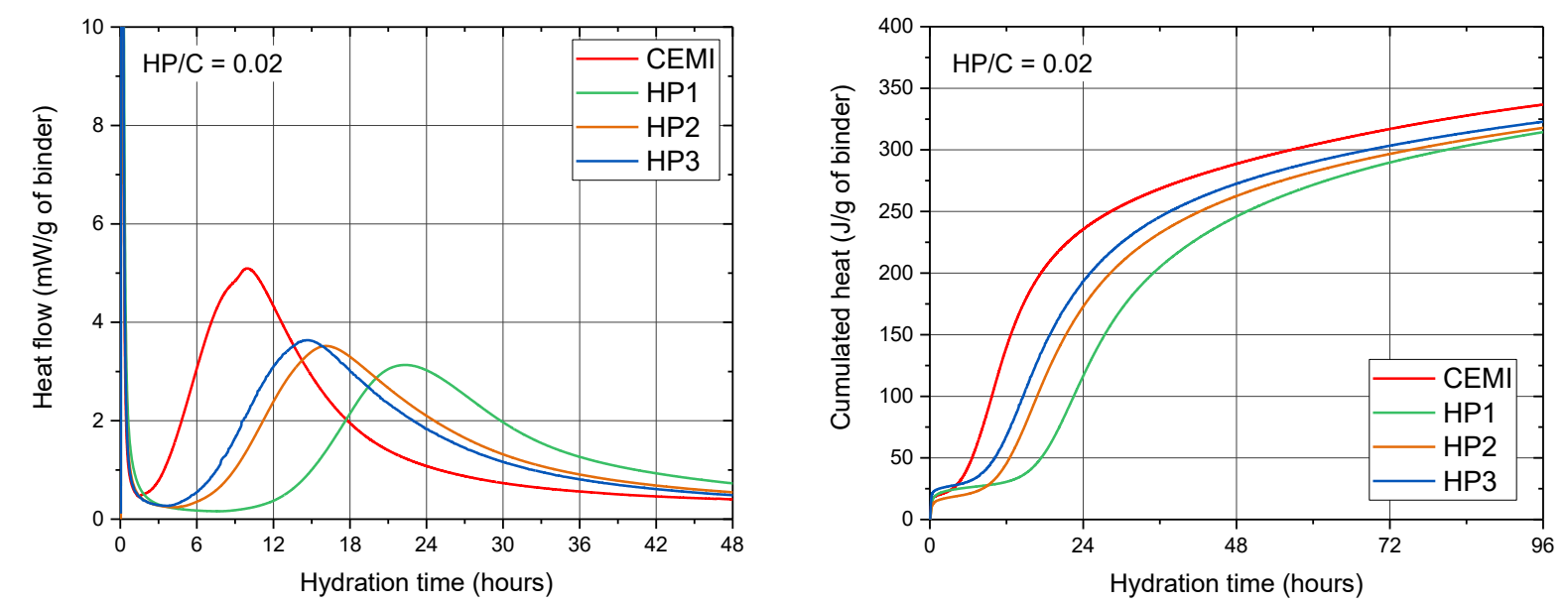

Figure 7. (a) Heat flow and (b) cumulated heat for pastes of CEMI, CEMI with HP1, HP2 and HP3 (HP/C = $\underline{0.02)}$

On the basis of these data, the CX' factors are determined (Table 4). The values of CX' confirm that HP1 is the less compatible hemp with CEMI. The values obtained for HP2 and HP3 are similar. They are in the orders of magnitude also measured for cement-wood mixtures [39].

In order to better understand these results, an analysis of the extractives from the shives - and in particular the sugars, which are liable to influence the setting of the hydraulic binders - is conducted in the next part of this study. The first step is to define the optimal conditions for extraction of the free compounds present in the shives.

\subsection{Optimisation of extraction conditions}

To quantify the amount of extractives and sugars present in the different shives, it is necessary to define the extraction conditions. In this section, we describe how we optimised these conditions in order to extract the maximum amount of reducing sugars in solution, whilst sticking as closely as possible to the mixing conditions. All tests are conducted on HS1 aggregates. Based on the protocols used in the existing body of literature (Table 1), various parameters influencing the extraction of molecules in solution are studied, such as the immersion time, the mass ratio of water to shiv, or the type of alkali used to reproduce the basic medium of a cement. 


\subsubsection{Immersion time}

To evaluate the quantity of extractives as a function of immersion time, HS1 shiv is immersed in distilled water for 30 minutes, 4 hours, 24 hours and 48 hours with a W/HS ratio of 30 . The quantity of reducing sugars extracted in these different time periods is presented in Figure 8-a. We observe that the quantity of molecules extracted varies as a function of the immersion time and reaches a maximum value at an immersion time of four hours. The decrease in the quantity of sugars after 4 hours is attributable to the fact that the sugars are consumed by micro-organisms, which have already been found to be present by previous studies [7]. In addition, the $\mathrm{pH}$ of the solution changes from 6.5 to 5 after 40 days' immersion. This decrease in $\mathrm{pH}$ is linked to the formation of acids due to the action of the micro-organisms, which hydrolyse the polysaccharides after having consumed all the free sugars in solution in order to continue to grow. This result was also observed in another study [7]. Dosage of the real quantity of sugars extractible from the shiv, therefore, requires us to reduce the immersion time as much as possible to avoid their being consumed by the micro-organisms.
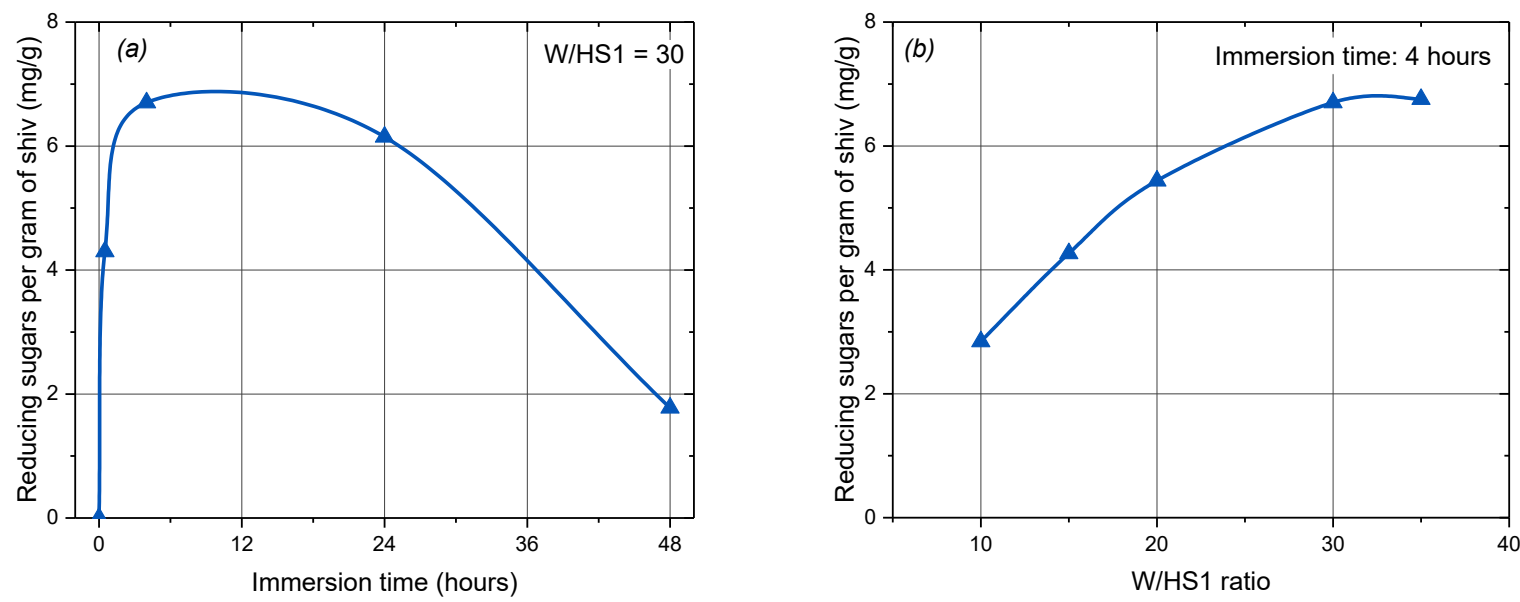

Figure 8. Amount of reducing sugars extracted from HS1 in water as function of (a) immersion time (for W/HS ratio of 30) and (b) W/HS ratio (after 4 hours of immersion)

\subsubsection{Influence of the water-to-shiv ratio}

To determine the water-to-shiv ratio, it is difficult to achieve conditions close to those in which a hemp concrete is mixed. Indeed, with a water/hemp shiv (W/HS) ratio of 2 , and water absorption by the aggregates which reaches over $200 \%$ in the space of a few minutes, it is impossible to collect an extraction solution. 
Thus, the minimum W/HS necessary in order to obtain the extraction solution is 10 . The quantity of reducing sugars extracted is determined after 4 hours of extraction. The influence if the quantity of water is assessed by dosing the extracted sugars into solutions with W/HS ratios of between 10 and 35 (Figure 8-b). The quantity of reducing sugars increases as a function of W/HS, up to a maximum value when $\mathrm{W} / \mathrm{HS}=30$. Beyond that point, the maximum quantity of extractives has been reached. It is therefore necessary to choose a high W/HS in order to extract the maximum amount of sugars. Indeed, the steeper the concentration gradient, the more the molecules diffuse from the more concentrated environment to the less concentrated one.

\subsubsection{Influence of alkali for extractions in basic environments}

In order to replicate the alkalinity of cement, extractions in a basic environment can be performed with solutions of soda $\mathrm{NaOH}$, lime $\mathrm{Ca}(\mathrm{OH})_{2}$ or a suspension of cement $[11,19,40]$. To monitor the type and quantity of alkaline elements, we chose to immerse the shiv samples in lime water $\mathrm{Ca}(\mathrm{OH})_{2}\left(1 \mathrm{~mol} . \mathrm{L}^{-1}\right)$ and in a solution of soda $\mathrm{NaOH}\left(2 \mathrm{~mol} . \mathrm{L}^{-1}\right)$. After dosage of the reducing sugars, we observe that, in comparison to extraction in water $\left(6.7 \pm 0.4 \mathrm{mg} \cdot \mathrm{g}^{-1}\right.$ of shiv), the quantity of sugars dosed is higher with the extraction in soda solution $\left(7.7 \pm 0.7 \mathrm{mg} \cdot \mathrm{g}^{-1}\right.$ of shiv), whereas it is lower in the presence of lime $\left(4.2 \pm 0.1 \mathrm{mg} \cdot \mathrm{g}^{-1}\right.$ of shiv). However, according to the literature, gas-phase chromatography dosages show that a larger quantity of molecules is extracted in a basic medium - notably more saccharides are extracted - whatever the alkaline agent used (extraction in $\mathrm{NaOH}$ and $\mathrm{Ca}(\mathrm{OH})_{2}$ for Sedan [7]). Whilst the results obtained for the extraction with $\mathrm{NaOH}$ show the same trend, the lower quantity of reducing sugars dosed in lime water is due to the presence of calcium ions. As is the case with cement, the calcium ions are capable of forming complexes with the sugars. When this happens, a portion of the sugars is no longer available to react with DNS, and the quantity of reducing sugars is therefore underestimated. Thus, a soda solution is chosen in order to be able to dose the extracted sugars in solution with DNS.

\subsubsection{Determination of the optimal extraction protocol to quantify the leachates}

With the aim of quantifying the level of extractive molecules and level of saccharides extracted from different shives, the extraction protocol defined on the basis of the above results, and described below, is used for the rest of this study. 
The extractions are carried out with hemp powder (HP) in order to optimise the quantity of extractives over a short period of immersion. Compared to raw shiv, immersing a hemp powder increases the exchange surface between the solid and the liquid. The use of a powder also improves the representativeness of the sample. We analyse $4 \mathrm{~g}$ of powder from the grinding and homogenisation of $100 \mathrm{~g}$ of shiv. In addition, the measured quantities of sugars extracted from hemp powder can be used to illuminate a discussion of the results of isothermal calorimetry obtained on cement pastes containing hemp powder (Figure 7).

A W/HP of 100 is chosen. This high value means we can optimise the extraction time at an hour. Indeed, with this ratio, the quantity of compounds extracted is $7.8 \mathrm{mg}$ per gram of hemp powder, whereas after 4 hours of immersion of aggregates with a W/HS of 30 , the quantity of extractives is $6.7 \mathrm{mg} / \mathrm{g}$ (Figure 8).

The extractions are carried out in distilled water at $20^{\circ} \mathrm{C}$ and $100^{\circ} \mathrm{C}$, to assess the influence of temperature, and replicate the same conditions as those used in other studies (Table 1), and in a solution of $\mathrm{NaOH}$ at a concentration of 2 mol.L-1 at $20^{\circ} \mathrm{C}$ to replicate the basic environment of a vegetal concrete.

In summary, the comparison of the extractives gained from the different kinds of shiv is based on extraction of hemp powder, in water at $20^{\circ} \mathrm{C}$ and at $100^{\circ} \mathrm{C}$, and in a 2 mol. $\mathrm{L}^{-1}$ soda solution at $20^{\circ} \mathrm{C}$, for one hour, with a W/HP of 100.

\subsection{Quantification of extractives from shives}

The extraction protocol defined in the previous section is used to compare the different types of shiv in the study. The mass percentage of the compounds extracted from the three types of shiv is determined to begin with. As sugars are often considered to be the compounds which are responsible for significant hydration delays, the content level of reducing sugars and the total quantity of sugars are then determined. The overall methodology of the study is illustrated in Figure 9. These results are then correlated with the isothermal calorimetry analyses presented in Figure 7. 


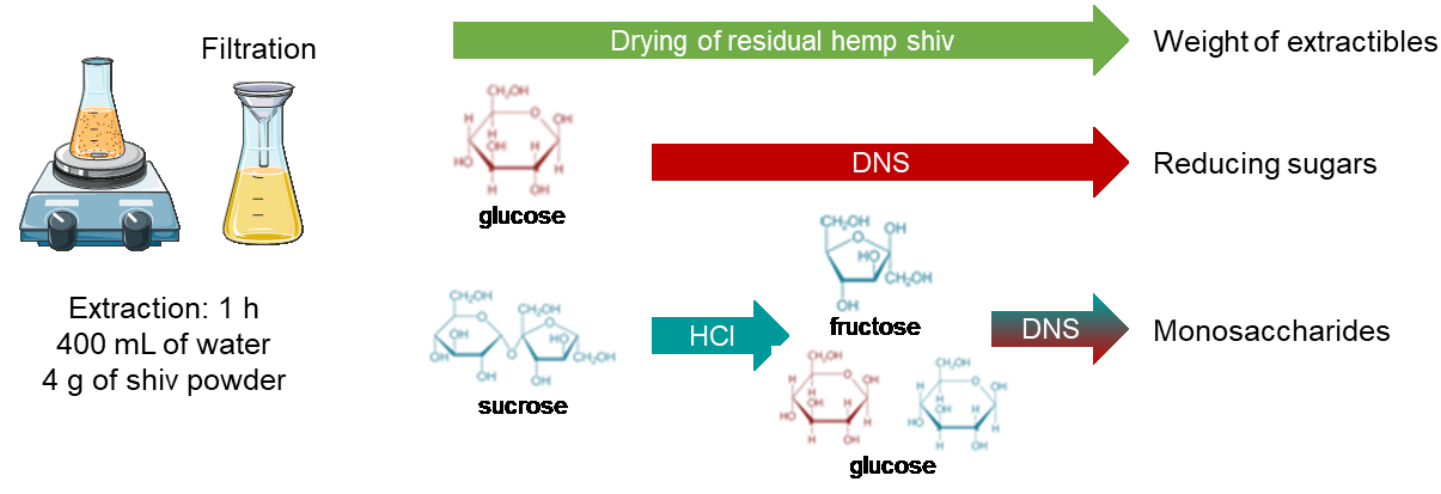

Figure 9. Analyses of solutions containing extractives compounds from shiv: weight of extractive, amount of reducing sugars, total amount of monosaccharides

\subsubsection{Extractive molecule content}

The level of extractives is calculated by finding the difference in mass of powder of dry hemp material before and after immersion. To do this, the extraction solution is filtered using a cellulose filter paper, with $8-12 \mu m$ pores; then the residue is dried at $105^{\circ} \mathrm{C}$ until it reaches a constant mass, and then weighed. The levels of extractives measured in the three different extraction conditions (water at $20^{\circ} \mathrm{C}$, water at $100^{\circ} \mathrm{C}$ and basic solution at $20^{\circ} \mathrm{C}$ ) are shown in Figure 10 . Whatever the type of shiv used, the level of extractives in water is greater at $100^{\circ} \mathrm{C}$ than at $20^{\circ} \mathrm{C}$, and higher still with extraction in a basic solution. By comparing the different hemp shives to one another, we find small differences in water at $20^{\circ} \mathrm{C}$, whereas more significant differences are observed in water at $100^{\circ} \mathrm{C}$ and in the basic environment. In any case, the highest quantity of extractives is measured on HS1; the hemp shiv containing least extractives is HS3. 


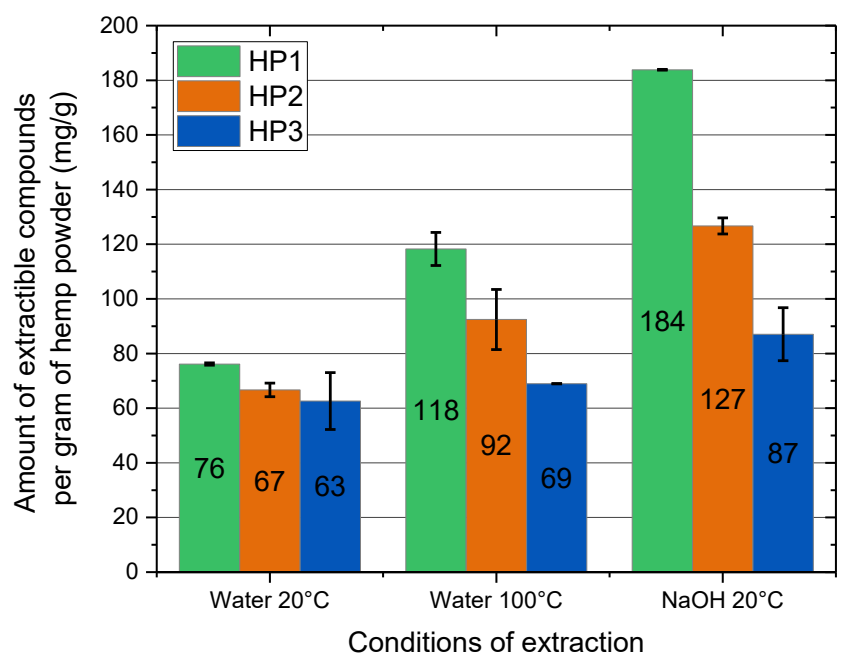

Figure 10. Content of extractive molecules for HP1, HP2 and HP3 after 1 hour in water at $20^{\circ} \mathrm{C}$, water at $100^{\circ} \mathrm{C}$ and in soda solution at $20^{\circ} \mathrm{C}$

The values obtained after extraction in water at $20^{\circ} \mathrm{C}$ are compared with the values obtained by Diquélou [3], for which the extraction is carried out in water over a period of 24 hours. For the three types of hemp shiv analysed in his study, one of which causes poor mechanical properties in mortars using the extraction solution as mixing water, the content of extractive molecules is between 32 and $44 \mathrm{mg} / \mathrm{g}$ of hemp. These levels are almost twice as low as those found after extraction in water for 1 hour in our study. Aside from the differences between the types of shiv, this can be attributed to a much lower W/HS ratio (10) and the use of aggregates. At $100^{\circ} \mathrm{C}$, the amounts of extractives are in the range of those obtained by Bourdot et al. [41].

\subsubsection{Dosages of saccharides}

As saccharides have been identified, in the earlier literature, as the main culprits delaying cement hydration, the quantity of sugars extracted in the different solutions was evaluated. The levels of reducing sugars extracted, determined by UV spectrometry after reaction with DNS, are illustrated in Figure 11. For the same type of hemp shiv, the quantity of extracted reducing sugars increases with temperature and with the basicity of the solution. These results obey the same trend as do the values of the total quantities of extractives. By comparing the levels of reducing sugars in the different types of hemp, we observe that HP1 filtrate contains significantly more reducing sugars than those of HP2 and HP3, whatever extraction solution is used. 


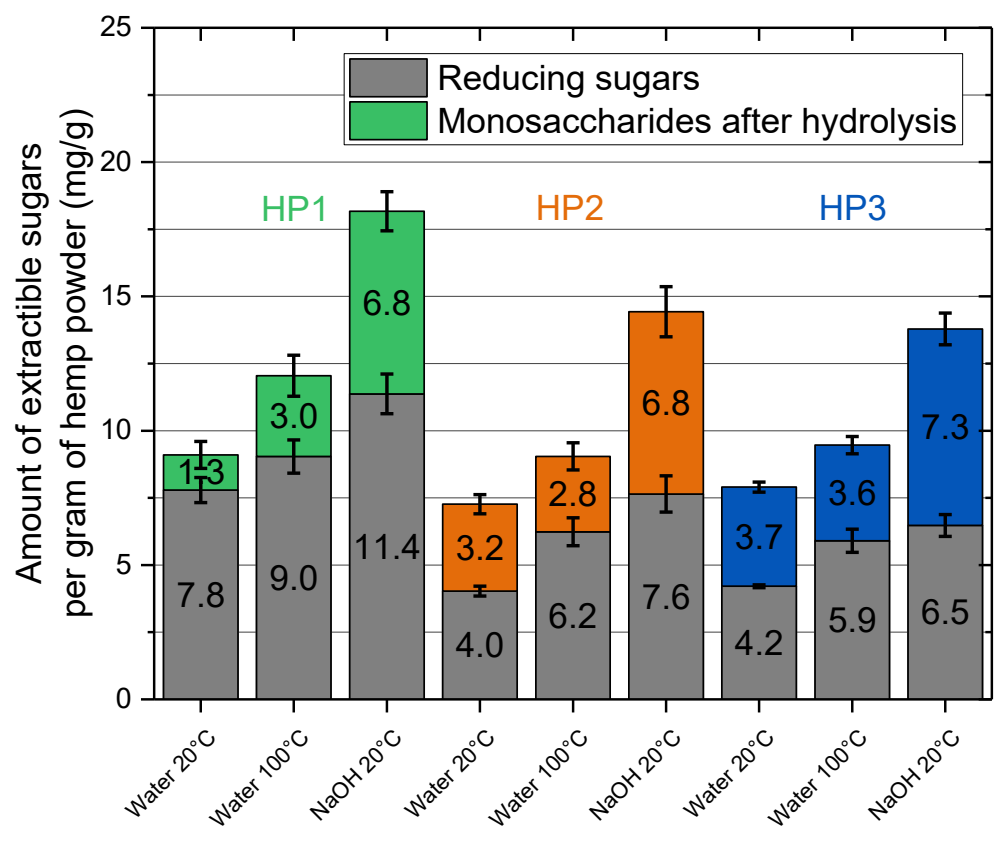

Conditions of extraction

Figure 11. Content of reducing sugars and of monosaccharides after hydrolysis per gram of shiv in extractive solution after 1 hours in water at $20^{\circ} \mathrm{C}$, water at $100^{\circ} \mathrm{C}$ and in soda solution at $20^{\circ} \mathrm{C}$

The ANOVA test has been used to assess if the differences of extractive contents are significantly different depending on the extraction conditions and the type of hemp shiv. The results are presented in Table 5 for the influence of temperature and extraction solution for a single type of shiv. Table 6 contains similar results about the differences between the different hemp shiv. If the value of the $p$ factor is lower than 0.05 , the differences are statistically significant.

First, the comparison of the extraction conditions for HP1, HP2 and HP3 (Table 5) shows that the differences observed are always significant as all $p$ values are lower than 0.05 . This conclusion is true both for reducing sugars and for monosaccharides. The higher value of $p$ is 0.04 for the comparison of reducing sugars after extraction of $\mathrm{HP} 3$ in water at $100^{\circ} \mathrm{C}$ and in $\mathrm{NaOH}$ solution. 
Table 5. ANOVA results for reducing sugars (1) and monosaccharides after hydrolysis (2) content determination: influence of extraction solution

\begin{tabular}{|c|c|c|c|c|c|c|c|c|c|}
\hline & \multicolumn{3}{|c|}{ HP1 } & \multicolumn{3}{|c|}{ HP2 } & \multicolumn{3}{|c|}{ HP3 } \\
\hline & $\begin{array}{l}\text { Water } \\
20^{\circ} \mathrm{C}\end{array}$ & $\begin{array}{l}\text { Water } \\
20^{\circ} \mathrm{C}\end{array}$ & $\begin{array}{l}\text { Water } \\
100^{\circ} \mathrm{C}\end{array}$ & $\begin{array}{l}\text { Water } \\
20^{\circ} \mathrm{C}\end{array}$ & $\begin{array}{l}\text { Water } \\
20^{\circ} \mathrm{C}\end{array}$ & $\begin{array}{l}\text { Water } \\
100^{\circ} \mathrm{C}\end{array}$ & $\begin{array}{l}\text { Water } \\
20^{\circ} \mathrm{C}\end{array}$ & $\begin{array}{l}\text { Water } \\
20^{\circ} \mathrm{C}\end{array}$ & $\begin{array}{l}\text { Water } \\
100^{\circ} \mathrm{C}\end{array}$ \\
\hline & $\begin{array}{l}\text { Water } \\
100^{\circ} \mathrm{C}\end{array}$ & $\begin{array}{l}\mathrm{NaOH} \\
20^{\circ} \mathrm{C}\end{array}$ & $\begin{array}{l}\mathrm{NaOH} \\
20^{\circ} \mathrm{C}\end{array}$ & $\begin{array}{l}\text { Water } \\
100^{\circ} \mathrm{C}\end{array}$ & $\begin{array}{l}\mathrm{NaOH} \\
20^{\circ} \mathrm{C}\end{array}$ & $\begin{array}{l}\mathrm{NaOH} \\
20^{\circ} \mathrm{C}\end{array}$ & $\begin{array}{l}\text { Water } \\
100^{\circ} \mathrm{C}\end{array}$ & $\begin{array}{l}\mathrm{NaOH} \\
20^{\circ} \mathrm{C}\end{array}$ & $\begin{array}{l}\mathrm{NaOH} \\
20^{\circ} \mathrm{C}\end{array}$ \\
\hline (1) & $2.7 \times 10^{-3}$ & $1.5 \times 10^{-6}$ & $1.4 \times 10^{-4}$ & $1.9 \times 10^{-6}$ & $1.7 \times 10^{-7}$ & $2.3 \times 10^{-3}$ & $2.5 \times 10^{-6}$ & $9.1 \times 10^{-8}$ & $4.0 \times 10^{-2}$ \\
\hline (2) & $1.3 \times 10^{-5}$ & $2 \times 10^{-10}$ & $5.8 \times 10^{-8}$ & $3.5 \times 10^{-5}$ & $7.7 \times 10^{-9}$ & $2.1 \times 10^{-7}$ & $1.2 \times 10^{-6}$ & $4 \times 10^{-10}$ & $2.1 \times 10^{-8}$ \\
\hline
\end{tabular}

Moreover, for extractions in water at $20^{\circ} \mathrm{C}$, the differences measured for the three types of shiv are all significant. In water at $100^{\circ} \mathrm{C}$ and in $\mathrm{NaOH}$ solution, the differences obtained for HP2 and HP3 are not significant as the values of $p$ are higher than 0.12 .

Indeed, we can conclude that the leachates obtained from HP1 contain significantly higher amounts of reducing sugars and monosaccharides than HP2 and HP3 extractives, whatever the extraction conditions. After extraction in water at $20^{\circ} \mathrm{C}$, the differences between HP2 and HP3 are less striking, but HP2 extractives contain significantly more sugars and monosaccharides in water at $20^{\circ} \mathrm{C}$. The amount of reducing sugars in HP2 in the $\mathrm{NaOH}$ solution is also significantly higher than in HP3. On the other hand, after extraction in water at $100^{\circ} \mathrm{C}$, equivalent quantities of reducing sugars and monosaccharides are dosed for both these types of shiv, because the calculated values of $p$ are respectively 0.25 and 0.12 .

Table 6. ANOVA results for reducing sugars (1) and monosaccharides after hydrolysis (2) content determination: influence of the nature of hemp shiv

\begin{tabular}{|c|c|c|c|c|c|c|c|c|c|}
\cline { 2 - 9 } \multicolumn{1}{c|}{} & \multicolumn{3}{c|}{ Water $20^{\circ} \mathbf{C}$} & \multicolumn{3}{c|}{ Water $100^{\circ} \mathbf{C}$} & \multicolumn{3}{c|}{ NaOH 20 } \\
\cline { 2 - 9 } & HP1 & HP1 & HP2 & HP1 & HP1 & HP2 & HP1 & HP1 & HP2 \\
\cline { 2 - 9 } & HP2 & HP3 & HP3 & HP2 & HP3 & HP3 & HP2 & HP3 & HP3 \\
\hline $\mathbf{( 1 )}$ & $4.9 \times 10^{-9}$ & $4.2 \times 10^{-9}$ & $3.8 \times 10^{-2}$ & $6.9 \times 10^{-6}$ & $1.3 \times 10^{-6}$ & 0.25 & $3.6 \times 10^{-6}$ & $5.8 \times 10^{-8}$ & $4.5 \times 10^{-3}$ \\
\hline $\mathbf{( 2 )}$ & $2.7 \times 10^{-5}$ & $2.8 \times 10^{-4}$ & $3.1 \times 10^{-3}$ & $1.1 \times 10^{-5}$ & $1.8 \times 10^{-5}$ & 0.12 & $1.6 \times 10^{-5}$ & $4.5 \times 10^{-7}$ & 0.19 \\
\hline
\end{tabular}


Whilst reducing sugars slow the reactions of hydration of the binders, Kochova et al. [23] showed that oligosaccharides, such as sucrose, have an even more significant delaying effect on the hydration. In order to compare the influence of the compounds extracted from the three types of shiv, it is important to know the total quantity of sugars extracted. To use UV spectrometry dosage after reduction of the DNS, the oligosaccharides and polysaccharides must be transformed into reducing monosaccharides. For that purpose, acid hydrolysis is carried out. The difference between the content of reducing sugars initially extracted and that obtained after total hydrolysis can be used to estimate the quantity of non-reducing sugars present in the solution. The results are presented in Figure 11.

For all types of shiv and all extraction solutions, the total quantity of monosaccharides is higher than the quantity of reducing sugars initially dosed. The hydrolysis demonstrates the presence of oligosaccharides in the hemp shiv extraction solutions.

Regardless of the extraction conditions, HP1 is the shiv which is richest in monosaccharides, both initially and in total. During extraction at $20^{\circ} \mathrm{C}$ in water, the low quantity of reducing sugars formed after acid hydrolysis demonstrates a predominance of reducing sugars extracted in relation to the oligosaccharides. However, in the same conditions, HP2 and HP3 contain more non-reducing sugars than HP1. In the case of extractions in water at $100^{\circ} \mathrm{C}$ and in a basic solution, the same quantity of monosaccharides stemming from the hydrolysis of oligosaccharides or polysaccharides is dosed whatever the type of hemp shiv.

Based on the ANOVA results reported in Table 5 and Table 6, we can conclude that, whatever the extraction conditions, HP1 has a significantly higher total sugar content than HP2 and HP3, notably for reducing sugars.

By comparing our results by immersion of the hemp powders in water at $20^{\circ} \mathrm{C}$ to those obtained by Diquélou [3], we dosed larger quantities of monosaccharides (respectively between 7 and $9 \mathrm{mg} / \mathrm{g}$ of hemp and between 5 and $7 \mathrm{mg} / \mathrm{g}$ of hemp with W/HS=10 and 24 hours immersion). The immersion duration of 24 hours enabled the microorganisms to consume the sugars in solution. 


\subsection{Influence of saccharides on the cement hydration}

To account for the differences in cement hydration delays observed as a function of the type of hemp shiv added, we hypothesised that the delays were due to the quantity of extractives present in the shives, and that the compounds which had the greatest impact were the sugars extracted from the hemp. To verify these hypotheses, isothermal calorimetry tests were conducted on a cement paste, to which we added quantities of standard sugars identical to those measured in the soda solutions in section 3.3. Indeed, these extraction conditions are as close as possible to those obtained in the presence of cement.

The effect of reducing sugars is simulated by glucose (Figure 11), and the effect of non-reducing polysaccharides dosed after hydrolysis is simulated by sucrose, whose significant delaying capacity has been observed in previous studies [9]. Although not all the non-reducing sugars extracted from the hemp material were sucrose, by adding it to the cement, we are able to maximise the visible effect of sugars on the setting. The sucrose molecule is made up of a molecule of glucose and a molecule of fructose, so after hydrolysis, the dosage of two monosaccharides into the hydrolysed solution is equivalent to a molecule of sucrose in the extractives solution. In reference to the mass concentrations of sugars dosed into the hemp extract solutions (Figure 11), for a cement paste made up with a HP/C of $0.02,0.6 \mathrm{mg}$ of glucose and $0.2 \mathrm{mg}$ of sucrose are added to the mixing water to simulate the effect of the sugars extracted from HP1, while $0.03 \mathrm{mg}$ of glucose and $0.2 \mathrm{mg}$ of sucrose are added to simulate the sugars extracted from HP3. The isothermal calorimetry results obtained for the different cement pastes are presented in Figure 12.

Compared with the hydration of the cement CEMI alone, the hydration of the cement pastes containing the standard sugars is delayed by 3 hours when we add the solution equivalent to HP1, and by 2 hours when we add the solution equivalent to HP3. The delays in hydration observed here confirm the influence of the quantity of sugars on the setting of the binder, because the higher the quantity of sugars, the greater is the delay.

If we compare the hydration delays obtained for these cement pastes with added standard sugars to the delays measured on the cement pastes containing hemp powders, we can see that, in spite of the addition of quantities of sugars equivalent to those extracted from the vegetal powders and the use of sucrose, which significantly delays setting, the hydration of the cements containing glucose and sucrose is quicker than that 
of the cements containing hemp powders. For HP3, the hydration peaks are at 11.5 hours in the presence of standard sugars and 14.5 hours in the presence of hemp powder HP3, as compared to 9 hours for pure cement paste. Thus, we can say that sugars are responsible for around half the delay in setting which is observed in the presence of powder. It is notable that the particularly significant hydration delay with cement paste containing HP1, in comparison to equivalent cement paste with a 10-hour difference between the maxima of the two hydration peaks. The shifts in setting time observed between the cement pastes containing standard sugars and the cement pastes containing aggregate powders show that the sugars are not the only compounds extracted from the vegetal materials which are responsible for the delays in setting. Other molecules present in the hemp also influence the hydration of the cement.

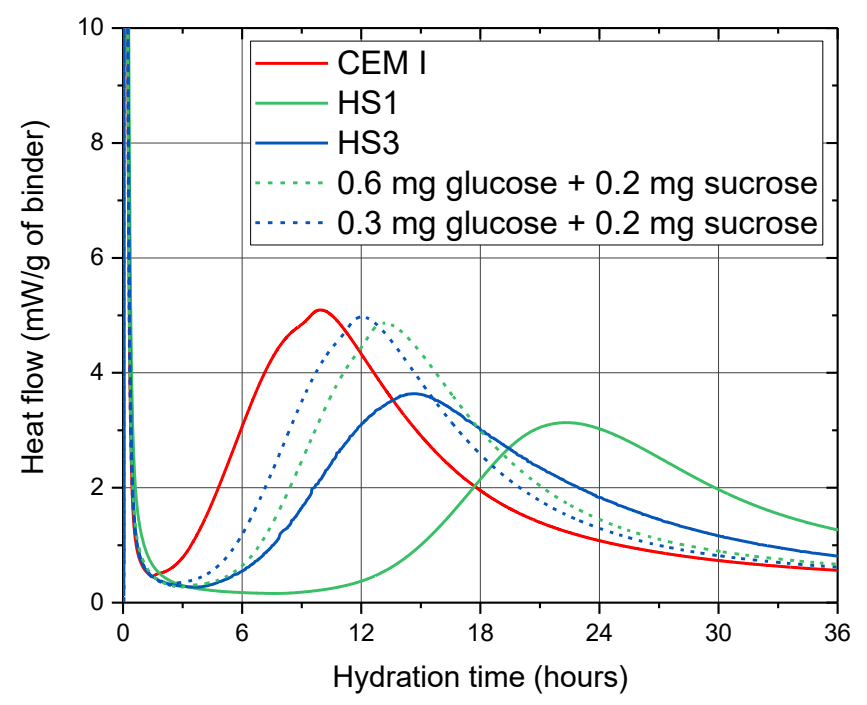

Figure 12. Heat flow for pastes of CEMI, CEMI with HP1 and HP3 $(H P / C=0.02)$ and with equivalent in sugars solutions with glucose and sucrose

\subsection{Other extractive compounds}

For the three types of hemp shiv studied, regardless of the extraction solution, we observe that the total quantity of sugars extracted varies between 7 and $18 \mathrm{mg} / \mathrm{g}$ of hemp shiv (Figure 11). 


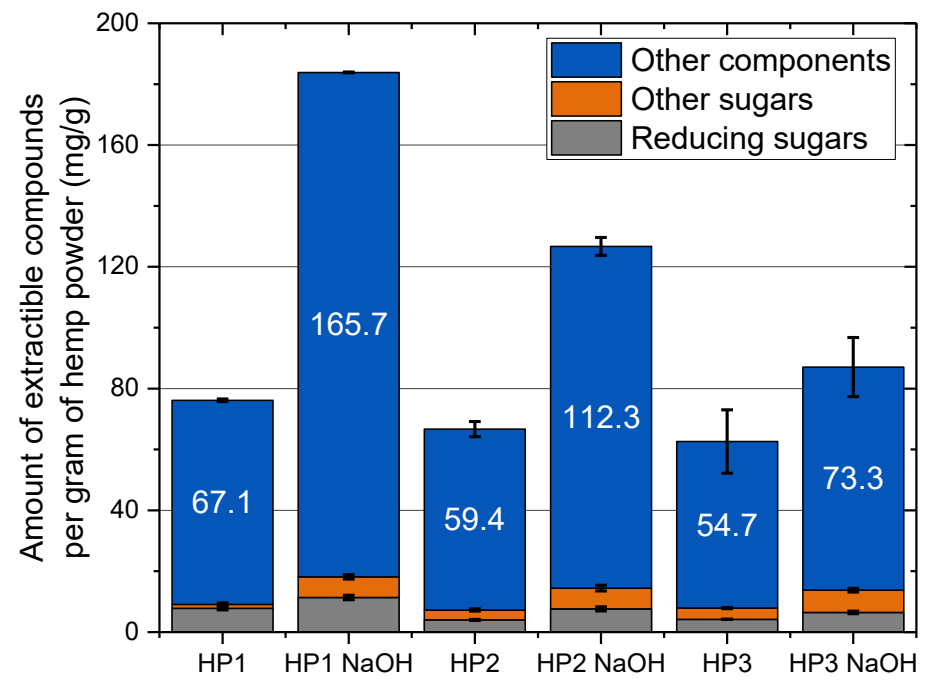

Figure 13. Composition of extractibles

Comparing it with the total quantity of extractives presented in Figure 10, this quantity of sugars corresponds to around $10 \%$ of the total extractives (Figure 13). A loss on ignition at $500^{\circ} \mathrm{C}$ for two hours on these extractives shows that they contain around $15 \%$ ash. Therefore, a large proportion of the compounds remain unidentified as in other studies [3]. These components can include some carbohydrates, like starches, lipids (oils, waxes...), proteins, hydrocarbons like terpenes or phenolic compounds.

In addition, when we look at the extraction solutions for the different hemp shives, e.g. in water at $20^{\circ} \mathrm{C}$ (Figure 14), the solution of HS1 extractives shows a more intense colouration than the extraction solutions for HS2 and HS3. The sugars cannot be responsible for this colouration, because they do not contain electron doublets which are sufficiently delocalised to absorb in the domain of visible light.

The colour of the three extractive solutions was determined by spectrophotometry, and the chromatic parameters are presented in Table 7. All the chromatic parameters of the three solutions are constant, except the value of $b^{*}$, which increases for the solution of HP1 extractives, confirmed by the stronger yellow colour observed for this solution. 
Table 7. Chromatic characterisation of extractive solutions

\begin{tabular}{lccc}
\hline Solution & $\mathbf{L}^{*}$ & $\mathbf{a}^{*}$ & $\mathbf{b}^{*}$ \\
\hline HP1 & $32.0 \pm 0.1$ & $-0.43 \pm 0.01$ & $3.20 \pm 0.02$ \\
HP2 & $32.4 \pm 0.1$ & $-0.37 \pm 0.01$ & $1.90 \pm 0.02$ \\
HP3 & $32.4 \pm 0.1$ & $-0.34 \pm 0.01$ & $1.64 \pm 0.02$ \\
\hline
\end{tabular}

By analysing the same solutions by UV-visible spectrometry (Figure 14), we observe that the spectra of the extraction solutions from all three hemp shives have the same shape. Only the absorbance of the extraction solution is higher for HS1 across the whole range of the spectrum. We can conclude from this that the compounds extracted from the three samples are of the same nature, and the concentration of extracted compounds in the HS1 immersion solution is higher. The higher absorbance between 400 and $500 \mathrm{~nm}$ of the HS1 extraction solution in comparison to HS2 and HS3 leads to the more intense yellow colouring of HS1.

In the spectral zone corresponding to UV light absorption (190-400nm), an absorption band at $280 \mathrm{~nm}$ shows the presence of extracted phenolic compounds [3], associated, for example, with lignin, with flavonoids, coumarins or tannins [42-44]. Like sugars, these phenolic compounds can influence the hydration of the cement $[3,45]$. However, it is not possible, by UV-Visible spectrometry, to identify the exact nature of these compounds. 


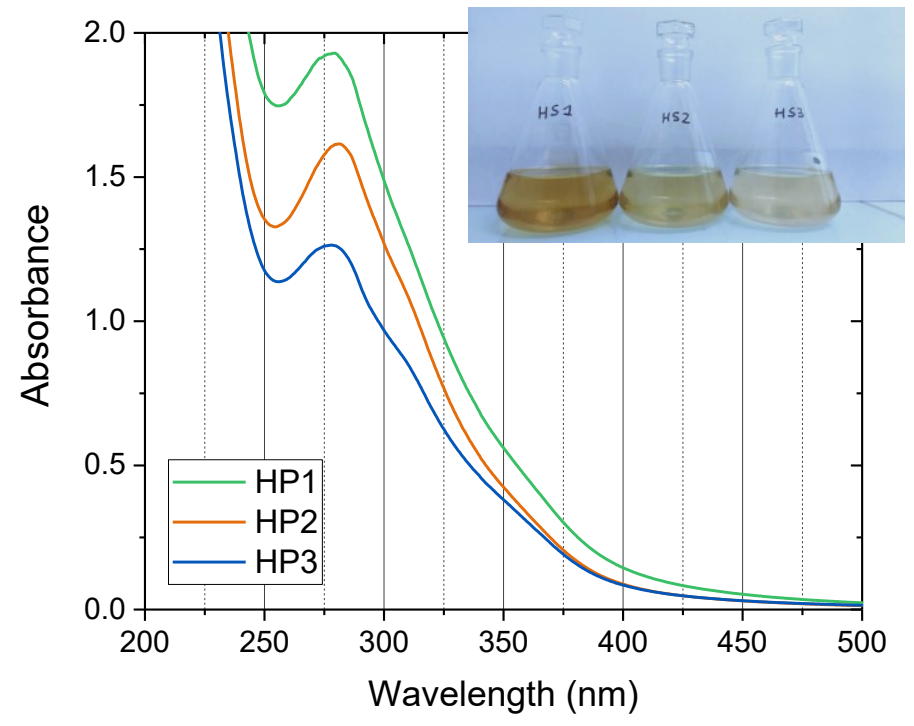

Figure 14. Pictures of extractive solutions in water at $20^{\circ} \mathrm{C}$ for HS1, HS2 and HS3, and UV-Visible spectra for the extractive solutions in water at $20^{\circ} \mathrm{C}$

\section{CONCLUSION}

Certain concretes made up with vegetal particles and mineral binders exhibit unsatisfactory mechanical strength, due to incomplete hydration of the hydraulic binder. This phenomenon can be put down to interactions between the free compounds present in the plant material and the binders, either delaying or totally preventing the mixture from setting. The objective of the current study is fix a methodology to extract and analyse the vegetal components which are responsible for these altered setting behaviours.

First, three types of hemp shiv were used to characterise their influence on the cement hydration, by isothermal calorimetry. These analyses showed that when we increase the quantity of hemp powder added $(\mathrm{HP} 1 / \mathrm{C}=0.01,0.05$ and 0.1$)$, the peak for hydration of the $\mathrm{C}_{3} \mathrm{~S}$ in the binder shifts towards later times. When the cement paste contains a HP1/C of 0.1 , the peak is no longer visible, and only the hydration of the aluminates is observed over short time periods. By comparing the influence of the three types of hemp shiv, it is possible to demonstrate that HS1 is indeed the product which most delays the setting.

To draw the link between the delay in setting and the extractive compounds from the hemp shives, an extraction protocol was developed by fixing temperature and $\mathrm{pH}$ of the solution, extraction time and solution- 
to-shiv ratio. Using this method, it has been shown that HS1 contains more extractives ( than the other two shives. In addition, the extractives from this shiv contain the largest quantity of sugars.

In reference to the quantities of sugars measured in the extraction solutions from the different shives, and formulating new cement pastes containing the same cement/sugar ratio using standard sugars, new measurements by isothermal calorimetry were taken to study the setting of the cement. In this case, we also observe a shift in setting time toward longer times, as happens in cement pastes containing vegetal powders. This shift is also more marked for the paste containing the same quantity of sugars as HS1. However, this shift is lesser than that which is measured with the hemp powders, which shows that sugars are not the only compounds which are responsible for the delays in setting. Indeed, they represent around $10 \%$ of the total mass of extractives. Analysis of the solutions by UV-visible spectroscopy showed that these phenolic compounds are also present. These compounds, such as lignin derivatives, can also impact the setting of binders.

Thus, the prospects for these studies are to more finely characterise the chemical composition of the vegetal materials, and in particular, their extractive compounds, to identify those which play a part in the setting of cements. This will help define criteria to select vegetal materials that are compatible with the hydraulic binders in order to be able to guarantee the performances of plant-based concretes used in construction.

\section{REFERENCES}

[1] Collectif SEBTP, Construire en Chanvre, Règles professionnelles d'exécution, 2012.

[2] G. Delannoy, S. Marceau, P. Glé, E. Gourlay, M. Guéguen-Minerbe, D. Diafi, I. Nour, S. Amziane, F. Farcas, Influence of binder on the multiscale properties of hemp concretes, Eur. J. Environ. Civ. Eng. (2018). doi:10.1080/19648189.2018.1457571.

[3] Y. Diquélou, E. Gourlay, L. Arnaud, B. Kurek, Impact of hemp shiv on cement setting and hardening: Influence of the extracted components from the aggregates and study of the interfaces with the inorganic matrix, Cem. Concr. Compos. $55 \quad$ (2015) 112-121. doi:10.1016/j.cemconcomp.2014.09.004.

[4] V. Sabathier, S. Louvel, G. Correa, C. Magniont, P. Evon, L. Labonne, Incidence of the water soluble 
compounds contained into lavender and sunflower bioaggregates on the hardening process of mineral binders, in: 2nd Int. Conf. Bio-Based Build. Mater., Clermont-Ferrand, 2017: pp. 62-68.

[5] C. Magniont, G. Escadeillas, Chemical Composition of Bio-aggregates and Their Interactions with Mineral Binders, in: Springer, Dordrecht, 2017: pp. 1-37. doi:10.1007/978-94-024-1031-0_1.

[6] M. Mathlouthi, P. Reiser, Sucrose: properties and applications, Blackie Academic \& Professional, 1995.

[7] D. Sedan, Etudes des interactions physico-chimiques aux interfaces fibres de chanvre/ciment: influence sur les propriétés mécaniques du composite, 2007. http://epublications.unilim.fr/theses/2007/sedan-david/sedan-david.pdf.

[8] B. Na, Z. Wang, H. Wang, X. Lu, Wood-cement compatibility review, Wood Res. 59 (2014) 813-825.

[9] N.L. Thomas, J.D. Birchall, The retarding action of sugars on cement hydration, Cem. Concr. Res. 13 (1983) 830-842. doi:10.1016/0008-8846(83)90084-4.

[10] M.C. Garci Juenger, H.M. Jennings, New insights into the effects of sugar on the hydration and microstructure of cement pastes, Cem. Concr. Res. 32 (2002) 393-399. doi:10.1016/S00088846(01)00689-5.

[11] G. Vaickelionis, R. Vaickelioniene, Cement hydration in the presence of wood extractives and pozzolan mineral additives, Ceramics-Silikáty. 50 (2006) 115-122.

[12] C. Niyigena, S. Amziane, A. Chateauneuf, Multicriteria analysis demonstrating the impact of shiv on the properties of hemp concrete, Constr. Build. Mater. 160 (2018) 211-222. doi:10.1016/J.CONBUILDMAT.2017.11.026.

[13] G.C.H. Doudart de la Grée, Q.L. Yu, H.J.H. Brouwers, Assessing the effect of CaSO4 content on the hydration kinetics, microstructure and mechanical properties of cements containing sugars, Constr. Build. Mater. 143 (2017) 48-60. doi:10.1016/J.CONBUILDMAT.2017.03.067.

[14] I.P. Wood, A. Elliston, P. Ryden, I. Bancroft, I.N. Roberts, K.W. Waldron, Rapid quantification of reducing sugars in biomass hydrolysates: Improving the speed and precision of the dinitrosalicylic acid assay, Biomass and Bioenergy. 44 (2012) 117-121. doi:10.1016/J.BIOMBIOE.2012.05.003.

[15] J.S. Laskowski, Q. Liu, C.T. O'Connor, Current understanding of the mechanism of polysaccharide adsorption at the mineral/aqueous solution interface, Int. J. Miner. Process. 84 (2007) 59-68. 
doi:10.1016/J.MINPRO.2007.03.006.

[16] A. Peschard, A. Govin, J. Pourchez, E. Fredon, L. Bertrand, S. Maximilien, B. Guilhot, Effect of polysaccharides on the hydration of cement suspension, J. Eur. Ceram. Soc. 26 (2006) 1439-1445. doi:10.1016/J.JEURCERAMSOC.2005.02.005.

[17] M. Bishop, A.R. Barron, Cement Hydration Inhibition with Sucrose, Tartaric Acid, and Lignosulfonate: Analytical and Spectroscopic Study, Ind. Eng. Chem. Res. 45 (2006) 7042-7049. doi:10.1021/IE060806T.

[18] N. Slabbert, Complexation of Condensed Tannins with Metal lons, in: Plant Polyphenols, Springer US, Boston, MA, 1992: pp. 421-436. doi:10.1007/978-1-4615-3476-1_23.

[19] A. Govin, Aspects physico-chimiques de l'interaction bois - ciment. Modification de l'hydratation du ciment par le bois, 2004. http://tel.archives-ouvertes.fr/docs/00/06/48/57/PDF/A-Govin.pdf.

[20] B.Y. Yang, R. Montgomery, Alkaline degradation of glucose: effect of initial concentration of reactants, Carbohydr. Res. 280 (1996) 27-45. doi:10.1016/0008-6215(95)00294-4.

[21] K. Miloski, K. Wallace, A. Fenger, E. Schneider, K. Bendinskas, Comparison of Biochemical and Chemical Digestion and Detection Methods for Carbohydrates, Am. J. Undergrad. Res. 7 (2008) $7-$ 18. doi:https://doi.org/10.33697/ajur.2008.015.

[22] B.J. Smith, L.R. Roberts, G.P. Funkhouser, V. Gupta, B.F. Chmelka, Reactions and Surface Interactions of Saccharides in Cement Slurries, Langmuir. 28 (2012) 14202-14217. doi:10.1021/la3015157.

[23] K. Kochova, K. Schollbach, F. Gauvin, H.J.H. Brouwers, Effect of saccharides on the hydration of ordinary Portland cement, Constr. Build. Mater. $150 \quad$ (2017) 268-275. doi:10.1016/J.CONBUILDMAT.2017.05.149.

[24] R.V. Ratiarisoa, C. Magniont, S. Ginestet, C. Oms, G. Escadeillas, Assessment of distilled lavender stalks as bioaggregate for building materials: Hygrothermal properties, mechanical performance and chemical interactions with mineral pozzolanic binder, Constr. Build. Mater. 124 (2016) 801-815. doi:10.1016/j.conbuildmat.2016.08.011.

[25] D. Sedan, C. Pagnoux, A. Smith, T. Chotard, Mechanical properties of hemp fibre reinforced cement: Influence of the fibre/matrix interaction, J. Eur. Ceram. Soc. 28 (2008) 183-192. 
doi:10.1016/j.jeurceramsoc.2007.05.019.

[26] G. Balčiunas, I. Pundiene, L. Lekunaite-Lukošiune, S. Vejelis, A. Korjakins, Impact of hemp shives aggregate mineralization on physical-mechanical properties and structure of composite with cementitious binding material, Ind. Crops Prod. $77 \quad$ (2015) 724-734. doi:10.1016/j.indcrop.2015.09.011.

[27] V. Nozahic, S. Amziane, Influence of sunflower aggregates surface treatments on physical properties and adhesion with a mineral binder, Compos. Part A Appl. Sci. Manuf. 43 (2012) 1837-1849. doi:10.1016/J.COMPOSITESA.2012.07.011.

[28] M. Nazerian, E. Gozali, M. Dahmardeh, The Influence of Wood Extractives and Additives on the Hydration Kinetics of Cement Paste and Cement-bonded Particleboard, J. Appl. Sci. 11 (2011) 2186-2192. doi:10.3923/jas.2011.2186.2192.

[29] Y.M. Wei, Y.G. Zhou, B. Tomita, Study of hydration behavior of wood cement-based composite II: effect of chemical additives on the hydration characteristics and strengths of wood-cement composites, J. Wood Sci. 46 (2000) 444-451. doi:10.1007/BF00765802.

[30] G.C.H. Doudart de la Grée, Q.L. Yu, H.J.H. Brouwers, Upgrading and Evaluation of Waste Paper Sludge Ash in Eco-Lightweight Cement Composites, J. Mater. Civ. Eng. 30 (2018) 04018021. doi:10.1061/(ASCE)MT.1943-5533.0002186.

[31] R. del Valle-Zermeño, J.E. Aubert, A. Laborel-Préneron, J. Formosa, J.M. Chimenos, Preliminary study of the mechanical and hygrothermal properties of hemp-magnesium phosphate cements, Constr. Build. Mater. 105 (2016) 62-68. doi:10.1016/J.CONBUILDMAT.2015.12.081.

[32] V. Nozahic, S. Amziane, G. Torrent, K. Saïdi, H. De Baynast, Design of green concrete made of plant-derived aggregates and a pumice-lime binder, Cem. Concr. Compos. 34 (2012) 231-241. doi:10.1016/j.cemconcomp.2011.09.002.

[33] AQC, Isolants biosourcés: points de vigilance, 2017. https://qualiteconstruction.com/publication/isolants-biosources-points-de-vigilance/ $\quad$ (accessed November 21, 2019).

[34] Y. Chen, Q.L. Yu, H.J.H. Brouwers, Acoustic performance and microstructural analysis of bio-based lightweight concrete containing miscanthus, Constr. Build. Mater. 157 (2017) 839-851. 
doi:10.1016/J.CONBUILDMAT.2017.09.161.

[35] S. Marceau, P. Glé, M. Guéguen-Minerbe, E. Gourlay, S. Moscardelli, I. Nour, S. Amziane, Influence of accelerated aging on the properties of hemp concretes, Constr. Build. Mater. (2017). doi:10.1016/j.conbuildmat.2016.11.129.

[36] S. Amziane, F. Collet, M. Lawrence, C. Magniont, V. Picandet, M. Sonebi, Recommendation of the RILEM TC 236-BBM : characterisation testing of hemp shiv to determine the initial water content , water absorption, dry density, particle size distribution and thermal conductivity, Mater. Struct. (2017). doi:10.1617/s11527-017-1029-3.

[37] S.A. Glantz, B.K. Slinker, T.B. Neilands, Primer of applied regression \& analysis of variance, McGraw-Hil, McGraw-Hill, 2016.

[38] S.A. Pasca, I.D. Hartley, M.E. Reid, R.W. Thring, Evaluation of Compatibility between Beetle-Killed Lodgepole Pine (Pinus Contorta var. Latifolia) Wood with Portland Cement, Materials (Basel). 3 (2010) 5311-5319. doi:10.3390/ma3125311.

[39] K. Kochova, V. Caprai, F. Gauvin, K. Schollbach, H.J.H. Brouwers, Investigation of local degradation in wood stands and its effect on cement wood composites, Constr. Build. Mater. 231 (2020) 117201. doi:10.1016/j.conbuildmat.2019.117201.

[40] D. Sedan, C. Pagnoux, T. Chotard, A. Smith, D. Lejolly, V. Gloaguen, P. Krausz, Effect of calcium rich and alkaline solutions on the chemical behaviour of hemp fibres, J. Mater. Sci. 42 (2007) 93369342. doi:10.1007/s10853-007-1903-4.

[41] A. Bourdot, C. Magniont, M. Lagouin, C. Niyigena, P. Evon, S. Amziane, Impact of Bio-Aggregates Properties on the Chemical Interactions with Mineral Binder, Application to Vegetal Concrete, J. Adv. Concr. Technol. 17 (2019) 542-558. doi:10.3151/jact.17.542.

[42] F. Shahidi, P. Ambigaipalan, Phenolics and polyphenolics in foods, beverages and spices: Antioxidant activity and health effects - A review, J. Funct. Foods. 18 (2015) 820-897. doi:10.1016/J.JFF.2015.06.018.

[43] I.M. de C. Tavares, E.S. Lago-Vanzela, L.P.G. Rebello, A.M. Ramos, S. Gómez-Alonso, E. GarcíaRomero, R. Da-Silva, I. Hermosín-Gutiérrez, Comprehensive study of the phenolic composition of the edible parts of jambolan fruit (Syzygium cumini (L.) Skeels), Food Res. Int. 82 (2016) 1-13. 
doi:10.1016/J.FOODRES.2016.01.014.

[44] A.F. Likhanov, Identification of intervarietal affinity of Rubus idaeus L. plants on biochemical profiles of phenolic compounds, Sci. Reports NULES Ukr. N7 (2014).

[45] T.-C. Chang, H.-T. Chang, C.-L. Wu, S.-T. Chang, Influences of extractives on the photodegradation of wood, Polym. Degrad. Stab. $95 \quad$ (2010) 516-521. doi:10.1016/J.POLYMDEGRADSTAB.2009.12.024. 